Article

\title{
An Integrated Decision-Making Model for Transformer Condition Assessment Using Game Theory and Modified Evidence Combination Extended by D Numbers
}

\author{
Lingjie Sun ${ }^{1,2}$, Yingyi Liu ${ }^{1, *}$, Boyang Zhang ${ }^{1}$, Yuwei Shang ${ }^{3}$, Haiwen Yuan ${ }^{1}$ and Zhao Ma ${ }^{3}$ \\ 1 School of Automation Science and Electrical Engineering, Beihang University, Beijing 100191, China; \\ sunlingjie@buaa.edu.cn (L.S.); zbyang@buaa.edu.cn (B.Z.); yhw@buaa.edu.cn (H.Y.) \\ 2 School of telecommunications, Taizhou Vocational \& Technical College, Taizhou 318000, China \\ 3 China Electric Power Research Institute, Beijing 100192, China; \\ shangyuwei@epri.sgcc.com.cn (Y.S.); ma_zhao@hotmail.co.uk (Z.M.) \\ * Correspondence: 09339@buaa.edu.cn; Tel.: +86-10-8231-6147
}

Academic Editor: Issouf Fofana

Received: 29 April 2016; Accepted: 18 August 2016; Published: 31 August 2016

\begin{abstract}
The power transformer is one of the most critical and expensive components for the stable operation of the power system. Hence, how to obtain the health condition of transformer is of great importance for power utilities. Multi-attribute decision-making (MADM), due to its ability of solving multi-source information problems, has become a quite effective tool to evaluate the health condition of transformers. Currently, the analytic hierarchy process (AHP) and Dempster-Shafer theory are two popular methods to solve MADM problems; however, these techniques rarely consider one-sidedness of the single weighting method and the exclusiveness hypothesis of the Dempster-Shafer theory. To overcome these limitations, this paper introduces a novel decision-making model, which integrates the merits of fuzzy set theory, game theory and modified evidence combination extended by $\mathrm{D}$ numbers, to evaluate the health condition of transformers. A four-level framework, which includes three factors and seventeen sub-factors, is put forward to facilitate the evaluation model. The model points out the following: First, the fuzzy set theory is employed to obtain the original basic probability assignments for all indices. Second, the subjective and objective weights of indices, which are calculated by fuzzy AHP and entropy weight, respectively, are integrated to generate the comprehensive weights based on game theory. Finally, based on the above two steps, the modified evidence combination extended by D numbers, which avoids the limitation of the exclusiveness hypothesis in the application of Dempster-Shafer theory, is proposed to obtain the final assessment results of transformers. Case studies are given to demonstrate the proposed modeling process. The results show the effectiveness and engineering practicability of the model in transformer condition assessment.
\end{abstract}

Keywords: power transformer; multi-attribute decision-making (MADM); game theory; fuzzy analytic hierarchy process (AHP); D numbers

\section{Introduction}

As a key piece of equipment in power systems, the power transformer comprises up to $60 \%$ of the total investment in substations and affects the safety and stability of power supply [1,2]. With the rapid expansion of the power system network, sudden failures of transformers will affect the security of life and property more seriously than before [3]. Therefore, grasping the health condition of transformers accurately is of significant importance, which involves transformers' operation and 
maintenance [4]. Health diagnosis methods provide feasibility for changing the maintenance strategy and, accordingly, maximizing the practicable operating efficiency and optimum life, while minimizing the risk of premature failure $[5,6]$.

In past years, many techniques, such as neural network [7], support vector machine [8] and fuzzy logic [9], were applied to transformer fault diagnosis. These approaches usually focused on a single factor (e.g., DGA analysis, thermal modeling, winding fault analysis, etc.). Results indicated that these research works could evaluate the transformer fault condition effectively to a certain extent. Nevertheless, these attempts were not sufficient to obtain an overall and precise health condition of the transformers [5,6]. They usually gave a qualitative description of transformers whether in good or bad condition. In fact, the transformer health condition is affected by many factors, which reflect its condition from different aspects, degrees and levels. The health condition of power transformers is often somewhere between good and bad. For example, some indices may have deviated from their permissible thresholds, but the overall condition is still acceptable. On the other hand, some indices may be below the thresholds, but the overall condition is bad, since timely maintenance is required. Therefore, it is difficult for power utilities to obtain accurate evaluation results due to varied information sources from transformers, which can be regarded as an MADM problem $[5,6]$.

To address such MADM problems, some researchers have attempted to integrate the merits of AHP and evidence theory to evaluate the electric primary devices including diverse condition information [5,10]. The AHP method, established by Satty, which has been successfully employed under many actual decision-making situations [11-14], is a popular approach for determining the weights of alternatives in MADM problems involving qualitative data [15,16]. In addition, the Dempster-Shafer theory (also called evidence theory), initially presented by Dempster [17] and then developed by Shafer [18], is applied to handle the uncertain information in MADM problems [5,6]. The kernel of evidence theory is the combination rule, which can be adopted to obtain an evaluation result considering various kinds of condition information [19].

However, these previous studies are still one-sided and unsystematic because of several challenges or drawbacks remaining.

- For the classical AHP approach, the scale of pair-wise comparison judgment, derived from experts, is confined to crisp numbers [20]. However, in many practical applications, such as condition assessment of transformers, expert objective predilection may be fuzzy [21], and the experts may not be willing to provide exact values for pair comparisons [22].

- For the calculation of weights, determining a suitable weight is a very important step in the decision process. However, both objective and subjective weight have limitations. The objective weight neglects the decision maker's knowledge and actual situation. On the contrary, the subjective weight is heavily influenced by expert experiences and prejudices, resulting in high subjectivity [23].

- For the traditional evidence theory, it is strongly confined to the definition of exclusiveness hypothesis and the completeness constraint [24]. Therefore, this limits the actual application of evidence theory, especially the application in the health condition assessment of transformers, including five intersection grades (health, sub-health, minor defect, major defect and critical defect) based on human judgment $[25,26]$. Unfortunately, little attention has been paid to the rigorous mathematical definition of evidence theory.

To effectively overcome these shortcomings of existing methods, several techniques, such as fuzzy extended AHP, game theory and D numbers, have been developed. The fuzzy extended AHP, extending the classical AHP by using a triangular fuzzy number [27], has become an outstandingly effective tool to determine the weights of evaluation criteria in an actual complex system. Recently, it has been successfully applied in many fields, like green product designs [28], ship selection [29] and teaching performance evaluation [30]. Game theory, a strategic bargaining behavior [31], has been developed and employed for various fields from economics to 
engineering [32]. It can play a better role when it comes to dealing with the conflicts among two or more participants [23]. Similarly, subjective and objective weight can be considered as two participants of a game, and the comprehensive weight is the result of the 'weight' game [23]. D numbers, a novel theory initially proposed by Deng [24], has become a powerful method to deal with the uncertainty in actual engineering applications due to its capacity of avoiding the mutually-exclusive hypothesis of the frame of discernment $[25,26,33,34]$.

Herein, a novel MADM model, which integrates the merits of fuzzy set theory, game theory and modified evidence combination extended by D numbers, is adopted to evaluate the health condition of transformers in this paper. Three factors, (i) dissolved gas analysis (DGA) date; (ii) electrical testing; (iii) oil testing and seventeen sub-indices are involved in the evaluate framework. The followings have been investigated in this paper: (i) adopting the fuzzy set theory to generate the original basic probability assignments for all indices; (ii) applying the game theory to obtain a comprehensive weight based on the subjective and objective weight, which are calculated by fuzzy extended AHP and the entropy weight, respectively; (iii) employing the distance of $\mathrm{D}$ numbers to modify original basic probability assignments and obtain final assessment results for transformers. The proposed model is verified by evaluating a realistic transformer and compared to a typical method. The results indicate that the model can evaluate the transformer health condition effectively.

This paper unfolds in the following fashion. Section 2 presents the framework for transformer condition assessment. Section 3 demonstrates the detailed procedures of the condition assessment model, including the fuzzy set theory, game theory and modified evidence combination extended by D numbers. Section 4 takes two cases for example to show the efficiency of the model, and final conclusions are illustrated in Section 5.

\section{Framework for Transformer Condition Assessment}

During the whole service period of the power transformer, various subsystems of the power transformer are aging gradually. Although the health condition of the power transformer cannot be observed directly, it can be reflected by all kinds of condition information $[5,6]$. Thus, diverse evaluation indices are acquired to evaluate the health condition of the transformer, which is regarded as an MADM problem. The selected evaluation indices should be typical and reasonable, so as to the reflect health condition of the transformer. Based on the aging mechanisms and fault properties of the transformer, three factors, DGA data, electrical testing and oil testing, are chosen in the evaluation framework.

The evaluation framework, a four-layer structure, is established as shown in Figure 1. Level 1, the objective level, represents the final condition evaluation result of the power transformer. Level 2, the factor level, describes the condition information of the transformer from three aspects. Level 3, the sub-factors' level, involves corresponding indices' information. For example, $f_{1}=\left\{f_{11}, f_{12}, f_{13}, f_{14}, f_{15}\right\}$ represents the DGA data with five indices. Level 4 , the assessment result level, indicates the evaluation grades of each index.

Based on previous research [6,21] and experts' experiences, the evaluation grades, relating to maintenance purposes, can be divided into five grades (health, sub-health, minor defect, major defect and critical defect) and are given by:

$$
\begin{aligned}
H & =\left\{H_{1}, H_{2}, H_{3}, H_{4}, H_{5}\right\} \\
& =\{\text { health, sub - health, minor defect, major defect, critical defect }\}
\end{aligned}
$$

The relationship between the assessment grades and maintenance strategy is described in Table 1. 


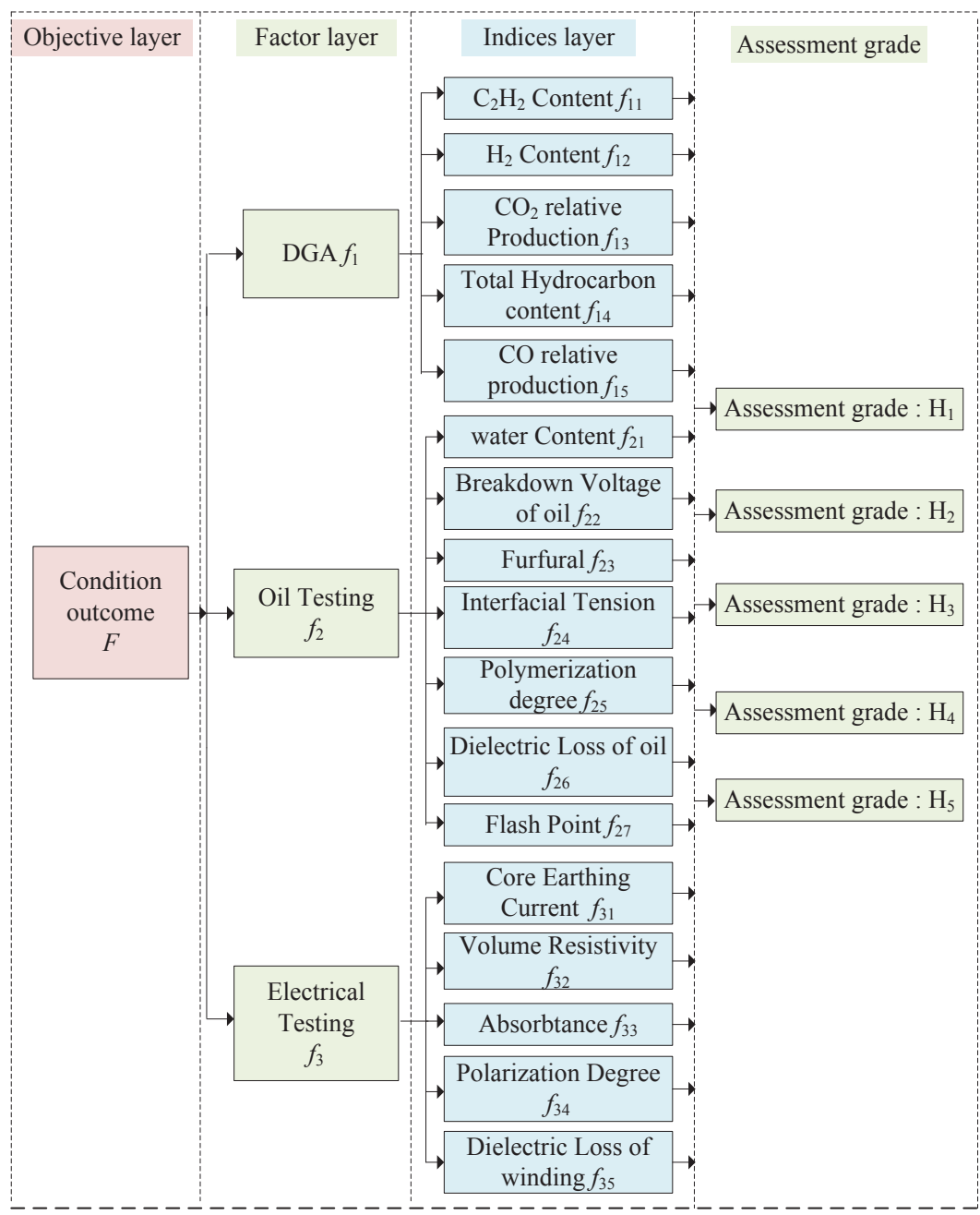

Figure 1. Condition information framework of the power transformer.

Table 1. Assessment grades' relation to the maintenance.

\begin{tabular}{cll}
\hline Grade & Condition Description & Maintenance Schedule \\
\hline Health & $\begin{array}{l}\text { Each property reaches the standard level, with a } \\
\text { sufficient margin for all of the corresponding critical } \\
\text { characteristic quantities and a strong ability to resist } \\
\text { risks and adapt to the environment. }\end{array}$ & One may properly delay the maintenance schedule. \\
\hline Sub-health & $\begin{array}{l}\text { All of the properties can reach the standard level, } \\
\text { but some of the critical characteristic quantities' values } \\
\text { are close to the standard limit values. Additionally, } \\
\text { the ability to resist risks and adapt to the } \\
\text { environment declines. }\end{array}$ & $\begin{array}{l}\text { Conduct maintenance as originally planned. } \\
\text { Pay attention to the parts that are close to standard } \\
\text { limit values of the characteristic quantities. }\end{array}$ \\
Minor defect & $\begin{array}{l}\text { Some of the critical characteristic quantities are out of } \\
\text { limit, but the comprehensive influence is small. There } \\
\text { appear slight defects of the ability to resist risks and } \\
\text { adapt to the environment. }\end{array}$ & $\begin{array}{l}\text { Arrange to carry out the maintenance schedule in } \\
\text { advance; intensify tour inspection, operation } \\
\text { monitoring, on-ling inspection, etc. }\end{array}$ \\
\hline \multirow{2}{*}{ Major defect } & $\begin{array}{l}\text { There appears serious degeneration of some properties, } \\
\text { and corresponding critical characteristic quantities are } \\
\text { out of the limit. The comprehensive influence is large, } \\
\text { and there exist obvious defects of the ability to resist } \\
\text { risks and adapt to the environment. }\end{array}$ & $\begin{array}{l}\text { Timely arrange to carry out the maintenance } \\
\text { schedule; intensify tour inspection, operation } \\
\text { monitoring, on-ling inspection, etc. The defect } \\
\text { elimination time is recommended to not exceed } \\
\text { one week. }\end{array}$ \\
\hline $\begin{array}{l}\text { The transformer cannot normally carry out the } \\
\text { regulated functions, but its functions can be recovered } \\
\text { after overhaul. }\end{array}$ & $\begin{array}{l}\text { Promptly arrange maintenance, and the defect } \\
\text { elimination time is recommended to not exceed } \\
\text { 24 h. }\end{array}$ \\
\hline Critical defect
\end{tabular}




\section{Methodology}

A novel hybrid MADM model, which integrates the merits of fuzzy set theory, game theory and modified evidence combination extended by $\mathrm{D}$ numbers, has been proposed in this paper. The assessment process consists of three key steps. First, the original basic probability assignments for all indices are obtained by the fuzzy set theory. Second, based on game theory, the subjective and objective weights of indices, which are calculated by fuzzy AHP and the entropy weight, respectively, are integrated to generate the comprehensive weights. Third, the modified evidence combination extended by D numbers is proposed to obtain the final assessing result.

\subsection{Fuzzy Set Theory}

Due to different dimensions or magnitudes, various indices need to be first normalized so as to obtain the membership grades for quantitative indices. Let $x_{i j}$ be the $j$-th index of the $i$-th factor, and the normalization mapping $x_{i j}: f \rightarrow[0,1]$ is given as follows [6].

If the indices are benefit attributes, the standardization process is:

$$
\gamma_{i j}=\frac{x_{i j}-\min \left(x_{i j}\right)}{\max \left(x_{i j}\right)-\min \left(x_{i j}\right)}
$$

If the indices are cost attributes, the standardization process is:

$$
\gamma_{i j}=\frac{\max \left(x_{i j}\right)-x_{i j}}{\max \left(x_{i j}\right)-\min \left(x_{i j}\right)}
$$

where $\gamma_{i j}$ is the standardized value.

The membership function is adopted widely in the condition assessment of electrical equipment. Nonetheless, there is no unified standard within fuzzy theory for constructing suitable membership functions [10]. Recently, a trapezoidal membership function is usually employed in the health diagnosis of transformers [35,36], and the trapezoidal model is also in accordance with the health condition of transformers [21]. Hence, the trapezoidal model is adopted to obtain the assessing grades in this paper. The design of the membership function is shown in Figure 2 [21] and can be described as follows.

$$
\begin{aligned}
& \begin{cases}f_{r}\left(x_{i j}\right)=\frac{\left(Z_{r+1}-x_{i j}\right)}{\left(Z_{\left.r_{+1}-Z_{r}\right)}\right.} & r=1,3,5,7 \\
f_{r}\left(x_{i j}\right)=\frac{\left(x_{i j}-Z_{r-1}\right)}{\left(Z_{r}-Z_{r-1}\right)} & r=2,4,6,8\end{cases} \\
& \left\{\begin{array}{l}
\mu_{1}\left(x_{i j}\right)= \begin{cases}1 & x_{i j} \leq Z_{1} \\
f_{1}\left(x_{i j}\right) & Z_{1} \leq x_{i j} \leq Z_{2} \\
0 & x_{i j}>Z_{2} \\
f_{2}\left(x_{i j}\right) & Z_{1} \leq x_{i j} \leq Z_{2} \\
1 & Z_{2} \leq x_{i j} \leq Z_{3} \\
f_{3}\left(x_{i j}\right) & Z_{3}<x_{i j}<Z_{4} \\
f_{4}\left(x_{i j}\right) & Z_{3}<x_{i j}<Z_{4} \\
1 & Z_{4} \leq x_{i j} \leq Z_{5} \\
f_{5}\left(x_{i j}\right) & Z_{5}<x_{i j}<Z_{6} \\
f_{6}\left(x_{i j}\right) & Z_{5}<x_{i j}<Z_{6} \\
1 & Z_{6} \leq x_{i j} \leq Z_{7} \\
f_{7}\left(x_{i j}\right) & Z_{7} \leq x_{i j} \leq Z_{8} \\
0 & x_{i j} \leq Z_{7} \\
f_{8}\left(x_{i j}\right) & Z_{7} \leq x_{i j} \leq Z_{8} \\
1 & x_{i j} \geq Z_{8}\end{cases}
\end{array}\right.
\end{aligned}
$$


After extensive field testing and validations, the interval values are given as: $Z_{1}=0.05, Z_{2}=0.25$, $Z_{3}=0.3, Z_{4}=0.45, Z_{5}=0.5, Z_{6}=0.75, Z_{7}=0.8, Z_{8}=0.95$, respectively.

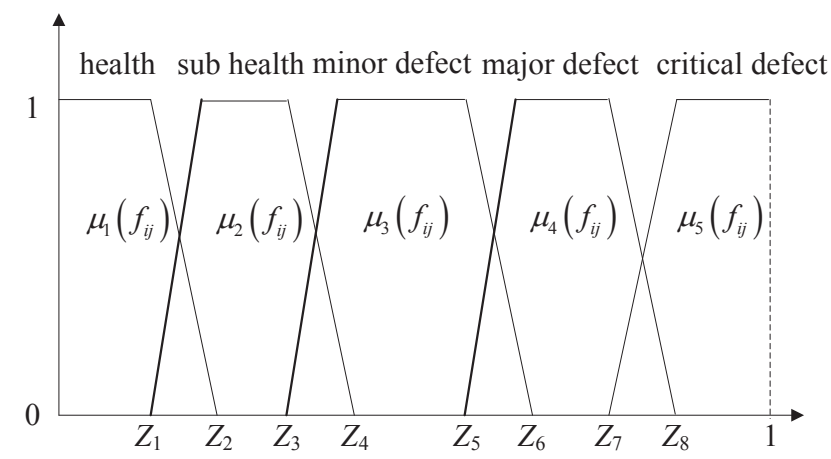

Figure 2. Membership function for the condition evaluation of indices.

By using Equations (2)-(5), the fuzzy membership matrix is then:

$$
Y_{i}(H)=\left[\begin{array}{cccc}
\mu_{1}\left(x_{i 1}\right) & \mu_{2}\left(x_{i 1}\right) & \cdots & \mu_{5}\left(x_{i 1}\right) \\
\mu_{1}\left(x_{i 2}\right) & \mu_{2}\left(x_{i 2}\right) & \cdots & \mu_{5}\left(x_{i 2}\right) \\
\vdots & \vdots & \vdots & \vdots \\
\mu_{1}\left(x_{i m}\right) & \mu_{2}\left(x_{i m}\right) & \cdots & \mu_{5}\left(x_{i m}\right)
\end{array}\right]
$$

where $Y_{i}(H)$ stands for the index membership matrix of the evaluation level of the $i$-th factor.

\subsection{Comprehensive Weights Based on Game Theory}

\subsubsection{Fuzzy Extended AHP}

Several fuzzy AHP methods have been developed to determine the weights of alternatives [37]. Among these methods, the fuzzy extended AHP, proposed by Chang [27], is employed widely in different application areas due to its lower computation complexity than the other methods [30]. In this paper, the fuzzy extended AHP is adopted to calculate the weights of alternatives based on experts' opinions.

Since the hierarchical structure is constructed, the triangular fuzzy comparison matrix [27], based on expert judgments, is given by:

$$
A=\left(a_{i j}\right)_{n \times n}=\left[\begin{array}{cccc}
(1,1,1) & \left(l_{12}, m_{12}, u_{12}\right) & \cdots & \left(l_{1 n}, m_{1 n}, u_{1 n}\right) \\
\left(l_{21}, m_{21}, u_{21}\right) & (1,1,1) & \cdots & \left(l_{2 n}, m_{2 n}, u_{2 n}\right) \\
\vdots & \vdots & \vdots & \vdots \\
\left(l_{n 1}, m_{n 1}, u_{n 1}\right) & \left(l_{n 2}, m_{n 2}, u_{n 2}\right) & \cdots & (1,1,1)
\end{array}\right]
$$

where:

$$
\begin{aligned}
& a_{i j}=\left(l_{i j}, m_{i j}, u_{i j}\right), a_{i j}^{-1}=\left(l_{i j}, m_{i j}, u_{i j}\right)^{-1}=\left(\frac{1}{u_{i j}}, \frac{1}{m_{i j}}, \frac{1}{l_{i j}}\right) \\
& i, j=1, \cdots, n \text { and } i \neq j
\end{aligned}
$$

The triangular fuzzy numbers and corresponding linguistic description are illustrated in Table 2. The linguistic description should be converted into fuzzy scales, which aims to be convenient for mathematical operation. The steps of fuzzy extended AHP are demonstrated as follows [27]. 
Table 2. Scale values of triangular fuzzy numbers.

\begin{tabular}{cc}
\hline Triangular Fuzzy Numbers & Linguistic Description \\
\hline$(1,1,1)$ & Equally important \\
$(2,3,4)$ & Moderately important \\
$(4,5,6)$ & Fairly important \\
$(6,7,8)$ & Strongly important \\
$(9,9,9)$ & Absolutely important \\
$(1,2,3)(3,4,5)(5,6,7)(7,8,9)$ & Intermediate preference values \\
\hline
\end{tabular}

Step 1: Sum up each row of the fuzzy comparison matrix $A$, then normalize the row sums. The fuzzy synthetic extent values of the $i$-th object are:

$$
S_{i}=\frac{R S_{i}}{\sum_{j=1}^{n} R S_{j}}=\frac{\sum_{j=1}^{n} a_{i j}}{\sum_{k=1}^{n} \sum_{j=1}^{n} a_{k j}}=\left[\frac{\sum_{j=1}^{n} l_{i j}}{\sum_{k=1}^{n} \sum_{j=1}^{n} u_{k j}}, \frac{\sum_{j=1}^{n} m_{i j}}{\sum_{k=1}^{n} \sum_{j=1}^{n} m_{k j}}, \frac{\sum_{j=1}^{n} u_{i j}}{\sum_{k=1}^{n} \sum_{j=1}^{n} l_{k j}}\right], i=1,2, \cdots, n
$$

Step 2: Compare the degree of possibility $\left(S_{i} \geq S_{j}\right)$. Thus:

$$
\begin{aligned}
& V\left(S_{1} \geq S_{2}\right)=1 \quad \text { iff } m_{1} \geq m_{2} \\
& V\left(S_{2} \geq S_{1}\right)=\operatorname{hgt}\left(S_{1} \cap S_{2}\right)=\mu_{S_{1}}(d)=\frac{l_{1}-u_{2}}{\left(m_{2}-u_{2}\right)-\left(m_{1}-l_{1}\right)}
\end{aligned}
$$

where $S_{1}=\left(l_{1}, m_{1}, u_{1}\right), S_{2}=\left(l_{2}, m_{2}, u_{2}\right)$ and $d$ is the intersection point between $\mu_{S_{1}}$ and $\mu_{S_{2}}$ (Figure 3 ).

Step 3: Compute the minimum degree of possibility. We have:

$$
V\left(S_{i} \geq S_{j} \mid j=1, \cdots, n ; j \neq i\right)=\min _{j \in\{1, \cdots, n\} j \neq i} V\left(S_{i} \geq S_{j}\right), i=1, \cdots, n
$$

Assume that:

$$
d\left(A_{i}\right)=\min _{j \in\{1, \cdots, n\} j \neq i} V\left(S_{i} \geq S_{j}\right), i=1, \cdots, n
$$

Then, the weight vector is:

$$
\mathbf{W}^{\prime}=\left(d\left(A_{1}\right), d\left(A_{2}\right), \cdots, d\left(A_{n}\right)\right)^{T}
$$

where $A_{i}(i=1,2, \ldots, n)$ are $n$ design alternatives.

Step 4: Normalize the weight vectors. The final weight vector is given by:

$$
\mathbf{W}=\left(W_{1}, W_{2}, \ldots, W_{n}\right)
$$

where $W_{1}, W_{2}, \ldots, W_{n}$ are non-fuzzy numbers.

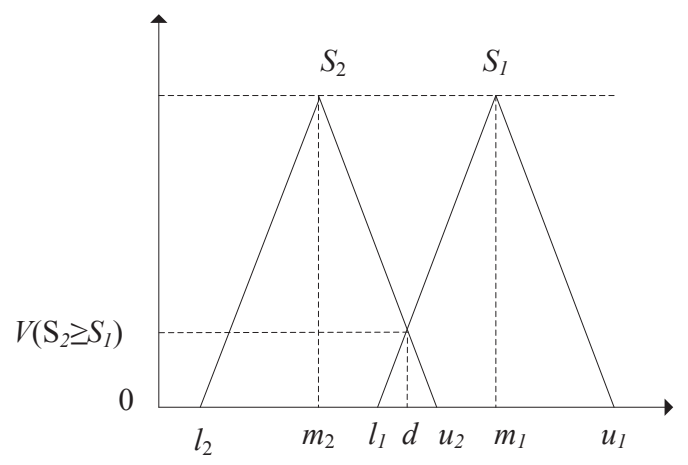

Figure 3. The degree of possibility $V\left(S_{2} \geq S_{1}\right)$. 


\subsubsection{Entropy Weight}

The information entropy theory was first set forth from thermodynamics to information systems by Shannon [38]. Based on the information entropy theory, the entropy weight can reflect the useful quantitative information of evaluation indices [39]. Assume that there are $m$ evaluation objects and $n$ indices for decision-making problems. The procedures are demonstrated as follows [40].

Step 1: Calculation of the entropy. Information entropy of index $j$ is:

$$
\begin{gathered}
f_{i j}=\frac{\gamma_{i j}}{\sum_{j=1}^{m} \gamma_{i j}} \\
H_{j}=-(\ln m)^{-1} \sum_{j=1}^{m} f_{i j} \ln f_{i j}
\end{gathered}
$$

where $\gamma_{i j}$ is the normalization value of the quantitative index.

Step 2: Acquisition of the weight. The weight acquired from information entropy is:

$$
\omega_{o j}=\frac{\left(1-H_{j}\right)}{\left(n-\sum_{j=1}^{m} H_{j}\right)}
$$

where $0 \leq w_{o j} \leq 1, \sum_{j=1}^{n} w_{o j}=1$

\subsubsection{Game Theory}

As discussed previously, there are certain limitations to consider a single weighting method under many situations. The objective weight neglects the decision-maker's knowledge and actual situation. On the contrary, the subjective weight is heavily influenced by expert experiences and some prejudices, resulting in high subjectivity. Therefore, the comprehensive weight, combining the subjective and objective weight with an effective algorithm, is more reasonable in the decision-making process.

Game theory, the research of strategic interaction, is an important branch of modern mathematics. Specifically, game theory is adopted to obtain the optimum equilibrium solution among two or more conflicts. In game theory, a decision is made either individually or collectively. Additionally, the decision can maximize the utility payoffs out of participants' expectations. Thus, a decision of either a consensus or compromise is suggested. Analogously, the comprehensive weight, which reaches a compromise between the subjective weight and the objective weight, can be regarded as an optimum equilibrium solution. The calculation steps of comprehensive weight based on game theory are described as below [23].

Step 1: Generate $m$ weights using $m$ kinds of weighting approaches. Then, establish a basic weight vector set $\mathbf{w}=\left\{\mathbf{w}_{\mathbf{1}}, \mathbf{w}_{\mathbf{2}}, \cdots, \mathbf{w}_{\mathbf{m}}\right\}$. Thus, a possible weight set is formed by $m$ vectors with the form of an arbitrary linear combination, expressed as:

$$
\mathbf{W}=\sum_{j=1}^{m} \alpha_{j} \mathbf{w}_{\mathbf{j}}^{\mathbf{T}}\left(\alpha_{j}>0\right)
$$

where $\mathbf{w}$ is a possible weight vector in set $\mathbf{W}$ and $\alpha_{j}$ is the weight coefficient.

Step 2: Calculate the optimum equilibrium weight vector $\mathbf{w}^{*}$ of the possible weight vector sets based on game theory, indicating that a consensus is reached among $m$ weights. Such a consensus can 
be taken as the optimization of the weight coefficient $\alpha_{j}$, which is a linear combination. The purpose of the optimization is to minimize the deviation between $\mathbf{w}$ and $\mathbf{w}_{\mathbf{j}}$ using the following formula.

$$
\min \left\|\sum_{k=1}^{n} \alpha_{k} \times \mathbf{w}_{\mathbf{k}}^{\mathbf{T}}-\mathbf{w}_{\mathbf{i}}^{\mathbf{T}}\right\|_{2} \quad(i=1,2, \cdots, n)
$$

Based on the differentiation property of the matrix, the condition of the optimal first-order derivative in Equation (17) is determined as:

$$
\sum_{k=1}^{n} \alpha_{k} \times \mathbf{w}_{\mathbf{i}} \times \mathbf{w}_{\mathbf{k}}^{\mathbf{T}}=\mathbf{w}_{\mathbf{i}} \times \mathbf{w}_{\mathbf{i}}^{\mathbf{T}}(i=1,2, \cdots, n)
$$

Then, we have:

$$
\left[\begin{array}{cccc}
\mathbf{w}_{\mathbf{1}} \cdot \mathbf{w}_{\mathbf{1}}^{\mathrm{T}} & \mathbf{w}_{1} \cdot \mathbf{w}_{\mathbf{2}}^{\mathrm{T}} & \cdots & \mathbf{w}_{\mathbf{1}} \cdot \mathbf{w}_{\mathbf{n}}^{\mathrm{T}} \\
\mathbf{w}_{\mathbf{2}} \cdot \mathbf{w}_{\mathbf{1}}^{\mathrm{T}} & \mathbf{w}_{\mathbf{2}} \cdot \mathbf{w}_{\mathbf{2}}^{\mathrm{T}} & \cdots & \mathbf{w}_{\mathbf{2}} \cdot \mathbf{w}_{\mathbf{n}}^{\mathrm{T}} \\
\vdots & \vdots & \vdots & \vdots \\
\mathbf{w}_{\mathbf{n}} \cdot \mathbf{w}_{\mathbf{1}}^{\mathbf{T}} & \mathbf{w}_{\mathbf{n}} \cdot \mathbf{w}_{\mathbf{2}}^{\mathbf{T}} & \cdots & \mathbf{w}_{\mathbf{n}} \cdot \mathbf{w}_{\mathbf{n}}^{\mathrm{T}}
\end{array}\right]\left[\begin{array}{c}
\alpha_{1} \\
\alpha_{2} \\
\vdots \\
\alpha_{n}
\end{array}\right]=\left[\begin{array}{c}
\mathbf{w}_{\mathbf{1}} \cdot \mathbf{w}_{\mathbf{1}}^{\mathrm{T}} \\
\mathbf{w}_{\mathbf{2}} \cdot \mathbf{w}_{\mathbf{2}}^{\mathrm{T}} \\
\vdots \\
\mathbf{w}_{\mathbf{n}} \cdot \mathbf{w}_{\mathbf{n}}^{\mathrm{T}}
\end{array}\right]
$$

Step 3: Compute the weight coefficient $\left(\alpha_{1}, \alpha_{2}, \cdots, \alpha_{n}\right)$ by using Equation (19), then normalize them using the following equation.

$$
\alpha_{j}^{*}=\alpha_{j} / \sum_{j=1}^{n} \alpha_{j}
$$

Step 4: Obtain the final comprehensive weight with the following formula:

$$
\mathbf{w}^{*}=\sum_{j=1}^{n} \alpha_{j}^{*} \cdot \mathbf{w}_{j}^{T}
$$

\subsection{Modified Evidence Combination Based on D Numbers}

Although the evidence theory is widely applied to solve MADM problems, many issues are still unsolved in some situations. Among these problems, the definition of mutually-exclusive and conflict evidence have attracted more attention. Recently, two methods, D numbers and weighted average combination, are proposed by Deng et al. $[24,41]$ to address the mentioned problems effectively. Inspired by the two methods, a modified evidence combination extended by D numbers is formulated as follows.

\subsubsection{Dempster-Shafer Theory}

Dempster-Shafer (D-S), also named evidence theory, is mainly introduced to solve the MADM problems with uncertainty. In the evidence theory, a sample set $\Theta$ that is collectively exhaustive and mutually exclusive, called a frame of discernment, is defined as [6]:

$$
\Theta=\left(H_{1}, H_{2}, \cdots H_{N}\right)
$$

The power set of $\Theta$ is described as $2^{\Theta}$, namely:

$$
2^{\Theta}=\left\{\phi,\left\{H_{1}\right\}, \cdots,\left\{H_{N}\right\},\left\{H_{1}, H_{2}\right\}, \cdots,\left\{H_{1}, H_{2}, \cdots, H_{i}\right\}, \cdots, \Theta\right\}
$$

If $A \in 2^{\Theta}, A$ is called a proposition. The combination rule is one of the most important performances in evidence theory. Suppose there are two pieces of evidence indicated by $m_{1}$ and 
$m_{2}$ on the same discernment framework $\Theta$, and the combination rule is performed [6], with the following signs:

$$
m(A)=\frac{1}{1-k} \sum_{A_{1} \cap A_{2}=A} m_{1}\left(A_{1}\right) m_{2}\left(A_{2}\right)
$$

where:

$$
k=\sum_{A_{1} \cap A_{2}=\Phi} m_{1}\left(A_{1}\right) m_{2}\left(A_{2}\right)
$$

In (25), $k$ is a conflict coefficient, which reflects the conflict degree between the two pieces of evidence $m_{1}\left(A_{1}\right)$ and $m_{2}\left(A_{2}\right)$.

\subsubsection{Numbers}

As mentioned above, the frame of discernment is a strong hypothesis of being mutually exclusive. However, it is inevitable that linguistic assessments based on human judgment intersect each other, such as "health", "sub-health", "minor defect","major defect" and "critical defect". Therefore, it is not reasonable to apply D-S theory under such circumstances. To address this problem, a novel technique, D numbers, was proposed.

Let $\Theta$ be a finite nonempty set, and a $D$ number is a mapping defined by $[24,26]$ :

$$
D: \Theta \rightarrow[0,1]
$$

with:

$$
\sum_{A \subseteq \Theta} D(A) \leq 1 \text { and } \mathrm{D}(\phi)=0
$$

where $\phi$ is an empty set and $A$ is a subset of $\Theta$.

Since the frame of discernment does not need to be a mutually-exclusive set in D numbers theory, the five grades of transformer health condition from health to critical defect can be regarded as a frame of discernment of D numbers.

\subsubsection{Distance between D Numbers}

A relative matrix, explaining the relationship between each D number, is described as follows [26]. Let the number $i$ and number $j$ of $m$ linguistic constants be expressed by $M_{i}$ and $M_{j}$, the union region between $M_{i}$ and $M_{j}$ be $U_{i j}$ and the intersection region between $M_{i}$ and $M_{j}$ be $T_{i j}$. The nonexclusive degree $N_{i j}$ is expressed as below.

$$
N_{i j}=\frac{T_{i j}}{U_{i j}}
$$

The relative matrix is established as:

$$
R=\left[\begin{array}{cccccc}
1 & N_{12} & \cdots & N_{1 i} & \cdots & N_{1 n} \\
N_{21} & 1 & \cdots & N_{2 i} & \cdots & N_{2 n} \\
\vdots & \vdots & \vdots & \vdots & \vdots & \vdots \\
N_{i 1} & N_{i 2} & \cdots & 1 & \cdots & N_{i n} \\
\vdots & \vdots & \vdots & \vdots & \vdots & \vdots \\
N_{n 1} & N_{n 2} & \cdots & N_{n i} & \cdots & 1
\end{array}\right]
$$

For instance, suppose $m$ linguistic constants are shown in Figure 4. The non-exclusive degree $N_{i j}$ is obtained to stand for the non-exclusive degree between two D numbers based on the region of union $U_{i j}$ and intersection $T_{i j}$ between $M_{i}$ and $M_{j}$. 
Then, an intersection degree of two subsets is described as below.

$$
I\left(T_{1}, T_{2}\right)=\frac{\sum N_{i j}}{\left|T_{1}\right| \cdot\left|T_{2}\right|}
$$

where $i \neq j, T_{1}, T_{2} \in 2^{\Theta}$. In the relative matrix $R$, the variable $i$ represents the row number of the first element of set $T_{1}$ and the variable $j$ represents the column number of the first element of set $T_{2}$. $\left|T_{1}\right|$ shows the cardinality of $T_{1}$, and $\left|T_{2}\right|$ shows the cardinality of $T_{2}$. Note that when $i=j, I=1$.

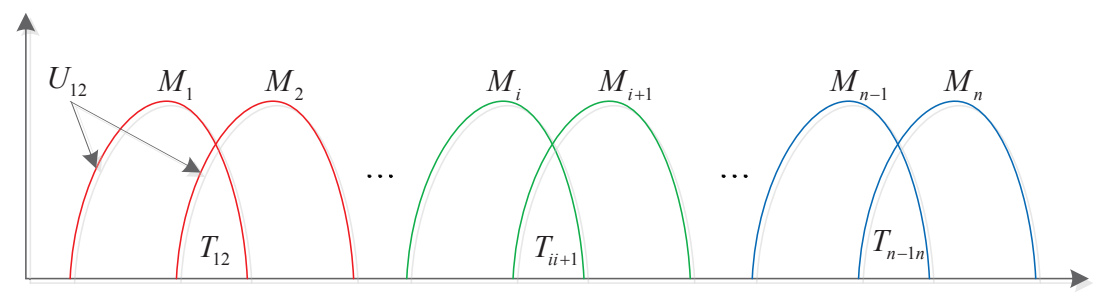

Figure 4. Example for linguistic constants.

Based on the above, the distance between two D numbers $d_{1}$ and $d_{2}$ is defined as:

$$
d_{D-\operatorname{number}\left(d_{1}, d_{2}\right)}=\sqrt{\frac{1}{2}\left(\overrightarrow{d_{1}}-\overrightarrow{d_{2}}\right)^{T} \underline{\underline{D}} \cdot \underline{\underline{I}}\left(\overrightarrow{d_{1}}-\overrightarrow{d_{2}}\right)}
$$

where $\underline{\underline{D}}$ and $\underline{\underline{I}}$ are two $2^{N} \times 2^{N}$ matrices. Their elements are defined as:

$$
\begin{aligned}
& \underline{\underline{D}}(A, B)=\left|\frac{A \cap B}{A \cup B}\right|, \quad A, B \in 2^{\Theta} \\
& \underline{\underline{I}}(A, B)=\left|\frac{\sum E_{i j}}{|A| \cdot|B|}\right|, \quad A, B \in 2^{\Theta}(\text { when } i=j, I=1)
\end{aligned}
$$

\subsubsection{Modified Evidence Combination Based on D Numbers}

After obtaining the distance of $\mathrm{D}$ numbers, we can construct a $n \times n$ matrix as:

$$
D=\left[\begin{array}{cccccc}
0 & d_{12} & \cdots & d_{1 j} & \cdots & d_{1 n} \\
\vdots & \vdots & \vdots & \vdots & \vdots & \vdots \\
d_{i 1} & d_{i 2} & \cdots & d_{i j} & \cdots & d_{i n} \\
\vdots & \vdots & \vdots & \vdots & \vdots & \vdots \\
d_{n 1} & d_{n 2} & \cdots & d_{n j} & \cdots & 0
\end{array}\right]
$$

Let $\operatorname{sim}\left(m_{i}, m_{j}\right)$ be the similarity value between $m_{i}$ and $m_{j}$, then the similarity value is given as [41]:

$$
\operatorname{Sim}\left(m_{i}, m_{j}\right)=1-D\left(m_{i}, m_{j}\right)
$$

It is obvious that the bigger the value of the distance is, the smaller the similarity of them will be, and vice versa. The similarity matrix is expressed as [41]:

$$
\operatorname{Sim}=\left[\begin{array}{cccccc}
1 & \operatorname{Sim}_{12} & \cdots & \operatorname{Sim}_{1 j} & \cdots & \operatorname{Sim}_{1 n} \\
\vdots & \vdots & \vdots & \vdots & \vdots & \vdots \\
\operatorname{Sim}_{i 1} & \operatorname{Sim}_{i 2} & \cdots & \operatorname{Sim}_{i j} & \cdots & \operatorname{Sim}_{i n} \\
\vdots & \vdots & \vdots & \vdots & \vdots & \vdots \\
\operatorname{Sim}_{n 1} & \operatorname{Sim}_{n 2} & \cdots & \operatorname{Sim}_{n j} & \cdots & 1
\end{array}\right]
$$


The support degree of each evidence is illustrated as [41]:

$$
\operatorname{Sup}\left(m_{i}\right)=\sum_{\substack{j=1 \\ j \neq i}}^{n} \operatorname{Sim}\left(m_{i}, m_{j}\right)
$$

To normalize $\operatorname{Sup}\left(m_{i}\right)$, the objective weights of evidence are obtained as [41]:

$$
w\left(m_{i}\right)=\frac{\operatorname{Sup}\left(m_{i}\right)}{\sum_{i=1}^{n} \operatorname{Sup}\left(m_{i}\right)}
$$

where $\sum_{i==^{\prime}}^{n} w\left(m_{i}\right)=1$.

Considering the relative importance of different factors in the power transformer, the optimum equilibrium weights of evidence (three factors), by integrating the objective and subjective weights of evidence, are determined based on game theory, described as:

$$
w^{*}=w\left(m_{i}\right) \oplus w^{\prime}\left(m_{j}\right)
$$

where $w^{\prime}\left(m_{j}\right)$ are the subjective weights of three factors (DGA date, electrical testing and oil testing).

After obtaining the optimum equilibrium weights of each piece of evidence, the new modified pieces of evidence are defined as [41]:

$$
\operatorname{MAE}(m)=\sum_{i=1}^{n}\left(w^{*} \times m_{i}\right)
$$

In this study, we take the modified pieces of evidence as independent of each other. If there are $n$ pieces of evidence, we can apply the traditional Dempster-Shafer's combination rule to combine the new modified evidence $n-1$ times.

\subsection{Procedures for Transformer Condition Assessment}

The detailed procedures of the novel multi-attribute decision-making model for transformer condition assessment are shown in Figure 5 and can be summarized as the following steps.

Step 1: Construct a framework of transformer condition assessment. Three factors and seventeen indices are involved in the assessment framework. The evaluation grades are divided into 5 grades (health, sub-health, minor defect, major defect, critical defect), defined by using Equation (1).

Step 2: Establish a fuzzy membership matrix. Due to the fact that various indices have different dimension values, a uniform standard, obtained by the fuzzy membership function, is needed in the assessment framework of the transformer. After determining the fuzzy membership function by using Equations (4) and (5), a fuzzy membership matrix for all of the indices is constructed in Equation (7).

Step 3: Calculate the subjective and the objective weight. The subjective weight is computed based on the fuzzy extended AHP by using Equations (8)-(14), and the objective weight is solved based on the entropy weight method by using Equations (15) and (16).

Step 4: Compute the comprehensive weight. As the subjective weight and objective weight are obtained, the comprehensive weight is generated based on the game theory by using Equations (17)-(22).

Step 5: Determine the original basic probability assignments. The original basic probability assignments are obtained through the additive weighting method, expressed as:

$$
M_{i}(H)=\sum_{j=1}^{n} w_{i j} Y_{i}(H)
$$


where $M_{i}(H)$ can be regarded as the original basic probability assignment of the $i$-th factor, $Y_{i}(H)$ stands for the index membership matrix of the evaluation level of the $i$-th factor and $w_{i j}$ reflects the comprehensive weight of index $f_{i j}$.

Step 6: Combine the modified pieces of evidence to generate the evaluation results of the transformer health condition by using Equations (24) and (25).

Step 7: Judge the final evaluation results based on the decision-making rule. The decision rule is defined as [42]:

$$
\left\{\begin{array}{l}
M\left(H_{1}\right)=\max \left\{M\left(H_{i}\right), H_{i} \in \Theta\right\} \\
M\left(H_{1}\right)-M\left(H_{2}\right)>\varepsilon
\end{array}\right.
$$

where $\varepsilon=0.04$.

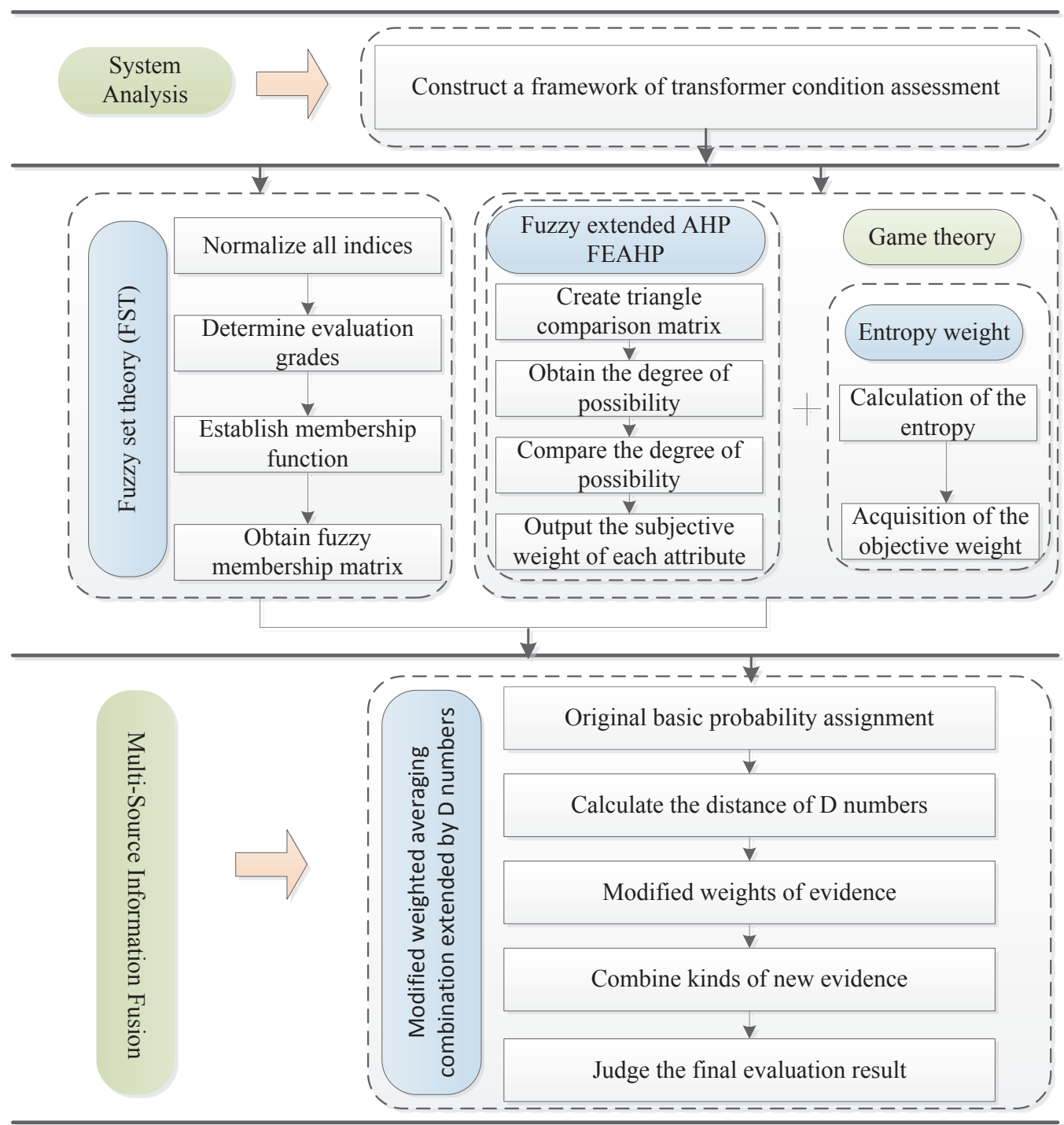

Figure 5. Flowchart of transformer condition assessment.

\section{Case Study}

\subsection{Case 1}

A $220-\mathrm{kV}$ main transformer (SFPSZ7-120000/220) used in the substation of Beijing in China is taken as an example to verify the effectiveness of the proposed model. The preventive test data in 2014 and 2015 are shown in Table 3, and the evaluation procedures are demonstrated as follows. 


\subsubsection{Assessment Grades by Fuzzy Set Theory}

From Table 3, the membership grades of indices are given by using Equations (2)-(5), and the results are shown in Table 4.

Table 3. Preventive test data of the transformer.

\begin{tabular}{ccccc}
\hline Index Term & 12 December 2013 & 16 September 2015 & Attention Values & Initial Value \\
\hline $\mathrm{C}_{2} \mathrm{H}_{2}$ & $1.2(\mu \mathrm{L} / \mathrm{L})$ & $2.1(\mu \mathrm{L} / \mathrm{L})$ & $10(\mu \mathrm{L} / \mathrm{L})$ & $0(\mu \mathrm{L} / \mathrm{L})$ \\
$\mathrm{C}_{2} \mathrm{H}_{4}$ & $10(\mu \mathrm{L} / \mathrm{L})$ & $42(\mu \mathrm{L} / \mathrm{L})$ & $50(\mu \mathrm{L} / \mathrm{L})$ & $5.3(\mu \mathrm{L} / \mathrm{L})$ \\
$\mathrm{CH}_{4}$ & $15.2(\mu \mathrm{L} / \mathrm{L})$ & $68(\mu \mathrm{L} / \mathrm{L})$ & $100(\mu \mathrm{L} / \mathrm{L})$ & $8.7(\mu \mathrm{L} / \mathrm{L})$ \\
$\mathrm{C}_{2} \mathrm{H}_{6}$ & $23(\mu \mathrm{L} / \mathrm{L})$ & $58(\mu \mathrm{L} / \mathrm{L})$ & $65(\mu \mathrm{L} / \mathrm{L})$ & $2.6(\mu \mathrm{L} / \mathrm{L})$ \\
$\mathrm{H}_{2}$ (hydrogen content in oil) & $48(\mu \mathrm{L} / \mathrm{L})$ & $65(\mu \mathrm{L} / \mathrm{L})$ & $150(\mu \mathrm{L} / \mathrm{L})$ & $5.1(\mu \mathrm{L} / \mathrm{L})$ \\
Water content & $7.2(\mathrm{mg} / \mathrm{L})$ & $13.1(\mathrm{mg} / \mathrm{L})$ & $25(\mathrm{mg} / \mathrm{L})$ & $2.6(\mathrm{mg} / \mathrm{L})$ \\
Breakdown voltage of oil & $49(\mathrm{kV})$ & $55(\mathrm{kV})$ & $35(\mathrm{kV})$ & $60(\mathrm{kV})$ \\
Furfural & $0.012(\mathrm{mg} / \mathrm{L})$ & $0.032(\mathrm{mg} / \mathrm{L})$ & $0.2(\mathrm{mg} / \mathrm{L})$ & $0(\mathrm{mg} / \mathrm{L})$ \\
Interfacial tension & $31(\mathrm{mN} / \mathrm{m})$ & $35(\mathrm{mN} / \mathrm{m})$ & $19(\mathrm{mN} / \mathrm{m})$ & $45(\mathrm{mN} / \mathrm{m})$ \\
Polymerization degree & 853 & 816 & 250 & 1000 \\
Dielectric loss of oil & $1.92 \%$ & $2.51 \%$ & $4 \%$ & $0.21 \%$ \\
Flash point & $153\left({ }^{\circ} \mathrm{C}\right)$ & $143\left({ }^{\circ} \mathrm{C}\right)$ & $130\left({ }^{\circ} \mathrm{C}\right)$ & $160\left({ }^{\circ} \mathrm{C}\right)$ \\
Core earthing current & $40(\mathrm{~mA})$ & $72(\mathrm{~mA})$ & $100(\mathrm{~mA})$ & $10(\mathrm{~mA})$ \\
Volume resistivity & $37 \times 10^{9}(\Omega \cdot \mathrm{m})$ & $35 \times 10^{9}(\Omega \cdot \mathrm{m})$ & $5 \times 10^{9}(\Omega \cdot \mathrm{m})\left(\leq 300{ }^{\circ} \mathrm{C}\right)$ & $65 \times 10^{9}(\Omega \cdot \mathrm{m})$ \\
Absorptance & 2.12 & 1.88 & 1.3 & 2.5 \\
Polarization index & 2.21 & 1.96 & 1.5 & 2.9 \\
Dielectric loss of winding & $0.38 \%$ & $0.42 \%$ & $0.6 \%$ & $0.15 \%$ \\
\hline
\end{tabular}

Table 4. Membership degrees to assess grades.

\begin{tabular}{cccccc}
\hline \multirow{2}{*}{ Membership Degrees of Indices } & \multicolumn{5}{c}{ Assessment Grades } \\
\cline { 2 - 6 } & $\boldsymbol{H}_{\mathbf{1}}$ & $\boldsymbol{H}_{\mathbf{2}}$ & $\boldsymbol{H}_{\mathbf{3}}$ & $\boldsymbol{H}_{\mathbf{4}}$ & $\boldsymbol{H}_{\mathbf{5}}$ \\
\hline$f_{11}$ & 0.2 & 0.8 & 0 & 0 & 0 \\
$f_{12}$ & 0 & 0 & 0 & 0.87 & 0.13 \\
$f_{13}$ & 0 & 0 & 0.4 & 0.6 & 0 \\
$f_{14}$ & 0 & 0 & 0 & 0.4 & 0.6 \\
$f_{15}$ & 0 & 0.27 & 0.73 & 0 & 0 \\
$f_{21}$ & 0 & 0 & 1 & 0 & 0 \\
$f_{22}$ & 0.25 & 0.75 & 0 & 0 & 0 \\
$f_{23}$ & 0.45 & 0.55 & 0 & 0 & 0 \\
$f_{24}$ & 0 & 0.47 & 0.53 & 0 & 0 \\
$f_{25}$ & 0 & 1 & 0 & 0 & 0 \\
$f_{26}$ & 0 & 0 & 0.7 & 0.3 & 0 \\
$f_{27}$ & 0 & 0 & 0.72 & 0.28 & 0 \\
$f_{31}$ & 0 & 0 & 0.24 & 0.76 & 0 \\
$f_{32}$ & 0 & 0 & 1 & 0 & 0 \\
$f_{33}$ & 0 & 0 & 1 & 0 & 0 \\
$f_{34}$ & 0 & 0 & 0.32 & 0.68 & 0 \\
$f_{35}$ & 0 & 0 & 0.6 & 0.4 & 0 \\
\hline
\end{tabular}

\subsubsection{Calculation of Weights}

Based on the fuzzy extended AHP and entropy weight, the subjective and objective weights of indices are calculated by using Equations (7)-(15). Then, combining the subjective and objective weights based on game theory, the comprehensive weights are obtained by using Equations (16)-(21). All types of weights of indices are shown in Table 5. For fuzzy AHP, the fuzzy comparison matrices of corresponding indices are provided in Appendix A (see Tables A1-A3).

Figure 6 describes the results in Table 5. As shown in Figure 6, the laws of the curves for the subjective and the objective weight, which are calculated by the fuzzy AHP and entropy weight, 
respectively, are not consistent, and the comprehensive weights based on game theory are optimum equilibrium values between the subjective and the objective weights. Actually, the weight coefficient reaching the Nash equilibrium decides the proportion of subjective and objective weight. Therefore, the comprehensive weights based on game theory are more reasonable to apply to determine the weights of indices in the evaluation process.

Table 5. Weights of indices.

\begin{tabular}{cccc}
\hline Indices & Fuzzy AHP & Entropy Weight & Game Theory \\
\hline$f_{11}$ & 0.3800 & 0.0300 & 0.1653 \\
$f_{12}$ & 0.2800 & 0.4000 & 0.3536 \\
$f_{13}$ & 0.1000 & 0.4300 & 0.3024 \\
$f_{14}$ & 0.0900 & 0.1300 & 0.1145 \\
$f_{15}$ & 0.1500 & 0.0100 & 0.0641 \\
$f_{21}$ & 0.1600 & 0.1500 & 0.1515 \\
$f_{22}$ & 0.2400 & 0.3700 & 0.3507 \\
$f_{23}$ & 0.2800 & 0.2400 & 0.2460 \\
$f_{24}$ & 0.0200 & 0.0100 & 0.0115 \\
$f_{25}$ & 0.1300 & 0.0100 & 0.0279 \\
$f_{26}$ & 0.1300 & 0.0100 & 0.0279 \\
$f_{27}$ & 0.0200 & 0.2000 & 0.1732 \\
$f_{31}$ & 0.4500 & 0.5300 & 0.5200 \\
$f_{32}$ & 0.3000 & 0.0500 & 0.1000 \\
$f_{33}$ & 0.0400 & 0.3200 & 0.2300 \\
$f_{34}$ & 0.0400 & 0.0500 & 0.0500 \\
$f_{35}$ & 0.1600 & 0.0500 & 0.0800 \\
\hline
\end{tabular}

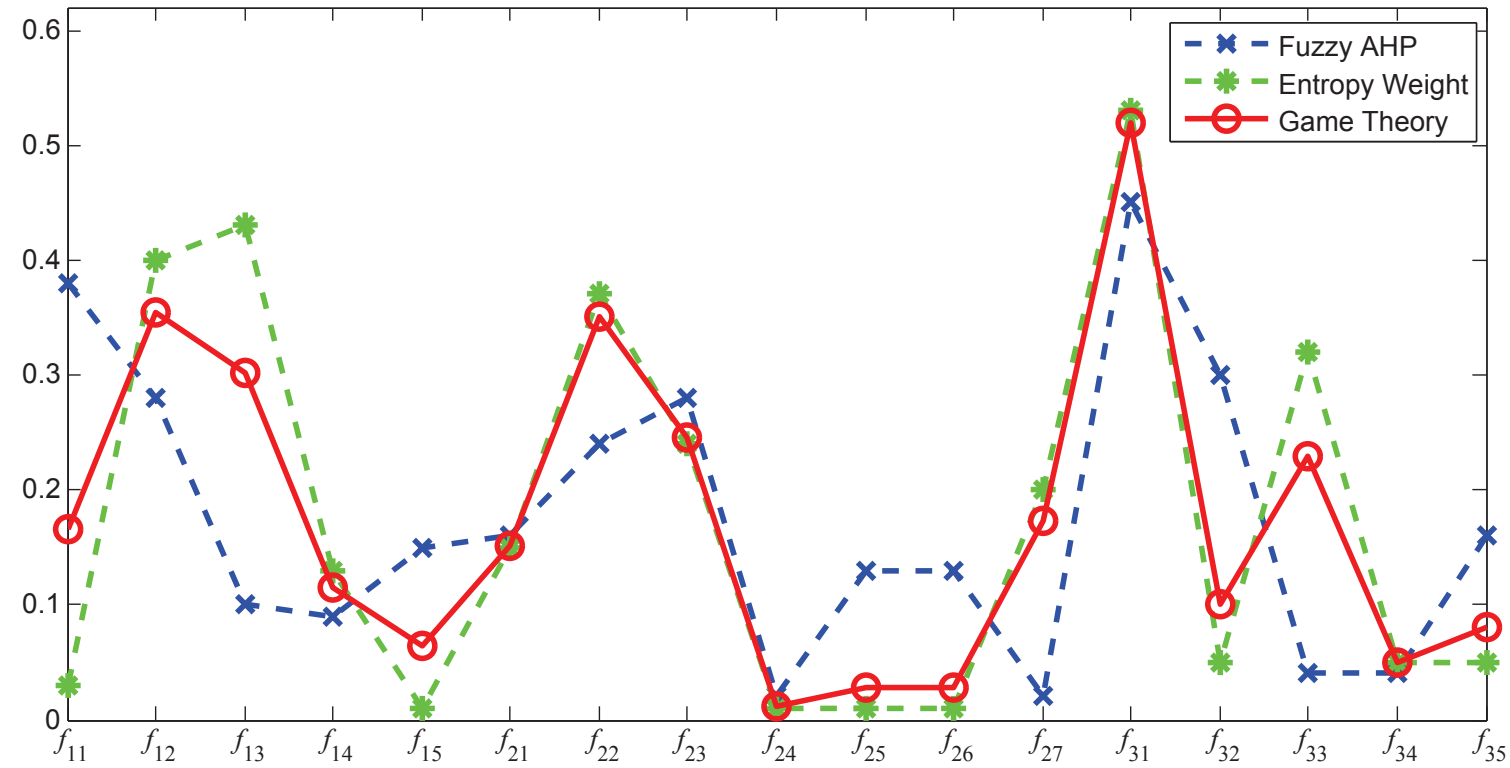

Figure 6. The calculation method of weights.

\subsubsection{Modified Evidence Combination Based on D Numbers}

From Tables 4 and 5, the original basic probability assignment matrix is obtained by using Equation (39): 


$$
M(H)=\left[\begin{array}{ccccc}
H_{1} & H_{2} & H_{3} & H_{4} & H_{5} \\
0.03 & 0.15 & 0.17 & 0.53 & 0.12 \\
0.2 & 0.43 & 0.3 & 0.07 & 0 \\
0 & 0 & 0.51 & 0.49 & 0
\end{array}\right]
$$

Based on the decision-making rule, the evaluation results of three factors are shown in Table 6. Figure 7 indicates the results in Table 6. As shown in Figure 7, the three curves corresponding to three different factors are various. Obviously, the evaluation results, considering an individual factor, are not accurate. Therefore, a multi-source information fusion is needed to determine the final health condition of the transformer.

Table 6. Basic probability assignment.

\begin{tabular}{ccccccc}
\hline \multirow{2}{*}{ Evidence } & \multicolumn{5}{c}{$\boldsymbol{M}(\boldsymbol{H})$} & \multirow{2}{*}{ Assessing Results } \\
\cline { 2 - 6 } & $\boldsymbol{H}_{\mathbf{1}}$ & $\boldsymbol{H}_{\mathbf{2}}$ & $\boldsymbol{H}_{\mathbf{3}}$ & $\boldsymbol{H}_{\mathbf{4}}$ & $\boldsymbol{H}_{\mathbf{5}}$ & \\
\hline$f_{1}$ & 0.03 & 0.15 & 0.17 & $\mathbf{0 . 5 3}$ & 0.12 & $\boldsymbol{H}_{4}$ \\
$f_{2}$ & 0.2 & $\mathbf{0 . 4 3}$ & 0.3 & 0.07 & 0 & $\boldsymbol{H}_{2}$ \\
$f_{3}$ & 0 & 0 & $\mathbf{0 . 5 1}$ & $\mathbf{0 . 4 9}$ & 0 & unknown \\
\hline
\end{tabular}

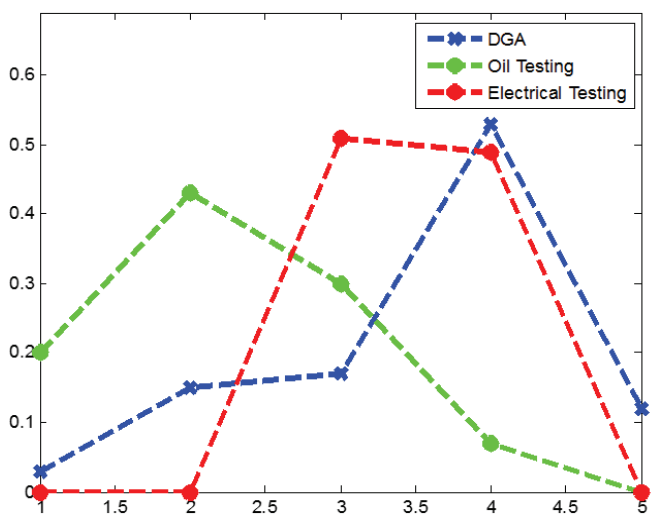

Figure 7. Evaluation grades of three factors.

As previously discussed, the basic probability assignment is regarded as three groups of D numbers. Therefore, we have:

$$
\begin{aligned}
& d_{1}\left(H_{1}\right)=0.03, d_{1}\left(H_{2}\right)=0.15, d_{1}\left(H_{3}\right)=0.17, d_{1}\left(H_{4}\right)=0.53, d_{1}\left(H_{5}\right)=0.12 \\
& d_{2}\left(H_{1}\right)=0.2, d_{2}\left(H_{2}\right)=0.43, d_{2}\left(H_{3}\right)=0.3, d_{2}\left(H_{4}\right)=0.07 \\
& d_{3}\left(H_{3}\right)=0.51, d_{3}\left(H_{4}\right)=0.49
\end{aligned}
$$

From Figure 3, in order to facilitate the calculation, the union region $\left(U_{i j}\right)$ and the intersection region $\left(T_{i j}\right)$ are given as:

$$
\begin{aligned}
& U_{H_{1} H_{2}}=0.45, U_{H_{2} H_{3}}=0.7, U_{H_{3} H_{4}}=0.65, U_{H_{4} H_{5}}=0.5 ; \\
& T_{H_{1} H_{2}}=0.2, T_{H_{2} H_{3}}=0.15, T_{H_{3} H_{4}}=0.25, T_{H_{4} H_{5}}=0.15 .
\end{aligned}
$$


Therefore, we have:

$$
\underline{\underline{D}}=\left[\begin{array}{lllll}
1 & 0 & 0 & 0 & 0 \\
0 & 1 & 0 & 0 & 0 \\
0 & 0 & 1 & 0 & 0 \\
0 & 0 & 0 & 1 & 0 \\
0 & 0 & 0 & 0 & 1
\end{array}\right], \underline{\underline{I}}=\left[\begin{array}{ccccc}
1 & 0.44 & 0 & 0 & 0 \\
0.44 & 1 & 0.21 & 0 & 0 \\
0 & 0.21 & 1 & 0.38 & 0 \\
0 & 0 & 0.38 & 1 & 0.3 \\
0 & 0 & 0 & 0.3 & 1
\end{array}\right]
$$

Based on the distance function method of $\mathrm{D}$ numbers, the distance matrix can be calculated by using Equations (28)-(33), given as:

$$
D=\left[\begin{array}{ccc}
0 & 0.44 & 0.25 \\
0.44 & 0 & 0.52 \\
0.25 & 0.52 & 0
\end{array}\right]
$$

By using Equations (34)-(37), the objective weights of evidence are generated as:

$$
w\left(m_{1}\right)=0.37 ; w\left(m_{2}\right)=0.29 ; w\left(m_{3}\right)=0.34
$$

In addition, from Table A4 in Appendix A, the subjective weights of evidence (three factors) are computed based on the fuzzy AHP, denoted as:

$$
w^{\prime}\left(m_{1}\right)=0.446 ; w^{\prime}\left(m_{2}\right)=0.329 ; w^{\prime}\left(m_{3}\right)=0.225
$$

Therefore, based on game theory, the optimum equilibrium weights of each piece of evidence are given as:

$$
w_{1}^{*}=0.44 ; w_{2}^{*}=0.32 ; w_{3}^{*}=0.23
$$

Then, using Equation (39), the modified pieces of evidence are calculated as:

$$
M(H)=[0.08,0.2,0.29,0.37,0.06]
$$

Finally, there are three pieces of evidence, and we take the traditional D-S combination rule two times. By using Equations (24) and (25), the final results are obtained as:

$$
M(H)=[0.01,0.1,0.29,0.61,0]
$$

\subsubsection{Analysis of the Evaluation Results}

The final evaluation results are shown in Table 7. As shown in Table 7, when two factors are combined, such as $f_{1}$ and $f_{2}$, the evaluation results indicate that the transformer health condition can be either good or bad, which gives little information on the maintenance schedule. Finally, when all three factors are combined and analyzed using the proposed method, the evaluation result clearly suggests a major defect since $H_{4}$ is far greater than the rest of the three evaluation grades.

The accuracy of this evaluation result is further consolidated by investigating the factual transformer condition. A field test suggests that the core is connected to the clamping pieces. Therefore, under the action of magnetic flux, the ring current is formed between the core and the clamping pieces. This leads to the deterioration of the insulation.

To conclude, the proposed method can effectively evaluate the health condition of the power transformer. 
Table 7. Result of evidence combination.

\begin{tabular}{ccccccc}
\hline \multirow{2}{*}{ Evidence } & \multicolumn{5}{c}{$\boldsymbol{M}(\boldsymbol{H})$} & \multirow{2}{*}{ Assessing Results } \\
\cline { 2 - 6 } & $\boldsymbol{H}_{\mathbf{1}}$ & $\boldsymbol{H}_{\mathbf{2}}$ & $\boldsymbol{H}_{\mathbf{3}}$ & $\boldsymbol{H}_{\mathbf{4}}$ & $\boldsymbol{H}_{\mathbf{5}}$ & \\
\hline$f_{1} \oplus f_{2}$ & 0.05 & 0.34 & 0.23 & 0.36 & 0.012 & unknown \\
$f_{1} \oplus f_{2} \oplus f_{3}$ & 0.01 & 0.1 & 0.29 & 0.61 & 0 & $H_{4}$ \\
\hline
\end{tabular}

\subsection{Case 2}

The performance of the presented model is further compared with the method proposed in the literature [6]. From [6], the original basic probability assignment matrix is given as:

$$
M(H)=\left[\begin{array}{ccccc}
H_{1} & H_{2} & H_{3} & H_{4} & H_{5} \\
0.0042 & 0.1112 & 0.3942 & 0.4904 & 0 \\
0 & 0.4152 & 0.2513 & 0.1452 & 0.1883 \\
0 & 0.4293 & 0.1867 & 0.2981 & 0.0859
\end{array}\right]
$$

Therefore, the D numbers are obtained as:

$$
\begin{aligned}
& d_{1}\left(H_{1}\right)=0.0042, d_{1}\left(H_{2}\right)=0.1112, d_{1}\left(H_{3}\right)=0.3942, d_{1}\left(H_{4}\right)=0.4904 \\
& d_{2}\left(H_{2}\right)=0.4152, d_{2}\left(H_{3}\right)=0.2513, d_{2}\left(H_{4}\right)=0.1452, d_{2}\left(H_{5}\right)=0.1883 \\
& d_{3}\left(H_{2}\right)=0.4293, d_{3}\left(H_{3}\right)=0.1867, d_{3}\left(H_{4}\right)=0.2981, d_{3}\left(H_{5}\right)=0.0859
\end{aligned}
$$

From the literature [6], the union region $\left(U_{i j}\right)$ and the intersection region $\left(T_{i j}\right)$ are given as:

$$
\begin{aligned}
& U_{H_{1} H_{2}}=\frac{4}{13}, U_{H_{2} H_{3}}=\frac{8}{13}, U_{H_{3} H_{4}}=\frac{8}{13}, U_{H_{4} H_{5}}=\frac{6}{13} \\
& T_{H_{1} H_{2}}=\frac{2}{13}, T_{H_{2} H_{3}}=\frac{2}{13}, T_{H_{3} H_{4}}=\frac{2}{13}, T_{H_{4} H_{5}}=\frac{2}{13} .
\end{aligned}
$$

Then, we have:

$$
\underline{\underline{D}}=\left[\begin{array}{lllll}
1 & 0 & 0 & 0 & 0 \\
0 & 1 & 0 & 0 & 0 \\
0 & 0 & 1 & 0 & 0 \\
0 & 0 & 0 & 1 & 0 \\
0 & 0 & 0 & 0 & 1
\end{array}\right], \underline{\underline{I}}=\left[\begin{array}{ccccc}
1 & 0.5 & 0 & 0 & 0 \\
0.5 & 1 & 0.25 & 0 & 0 \\
0 & 0.25 & 1 & 0.25 & 0 \\
0 & 0 & 0.25 & 1 & 0.33 \\
0 & 0 & 0 & 0.33 & 1
\end{array}\right]
$$

By using Equations (28)-(33), the distance matrix of D numbers is obtained as:

$$
D=\left[\begin{array}{ccc}
0 & 0.34 & 0.29 \\
0.34 & 0 & 0.11 \\
0.29 & 0.11 & 0
\end{array}\right]
$$

Based on Equations (34)-(37), the objective weights of evidence are computed as:

$$
w\left(m_{1}\right)=0.3 ; w\left(m_{2}\right)=0.34 ; w\left(m_{3}\right)=0.35
$$

In addition, the subjective weights of factors are given as:

$$
w^{\prime}\left(m_{1}\right)=0.446 ; w^{\prime}\left(m_{2}\right)=0.329 ; w^{\prime}\left(m_{3}\right)=0.225
$$

Therefore, based on game theory, the optimum equilibrium weights of each piece of evidence are generated as:

$$
w_{1}^{*}=0.4343 ; w_{2}^{*}=0.3332 ; w_{3}^{*}=0.2405
$$


By using Equation (39), the modified pieces of evidence can be given as:

$$
M(H)=[0.002,0.29,0.3,0.33,0.08]
$$

There are three pieces of evidence, and we combined the evidence two times. The final assessment results are given as:

$$
M(H)=[0,0.28,0.3,0.42,0]
$$

In the literature [6], the evaluation results are provided as:

$$
M^{\prime}(H)=[0.0011,0.2445,0.3432,0.3472,0.0336]
$$

Figure 8 describes the comparison results between the proposed method and the compared method. As shown in Figure 8, the final assessing result of the proposed method is confirmed to be grade $H_{4}\left(H_{4}=0.42\right)$, which accurately reflects the actual condition of the transformer according to the literature [6]. Nevertheless, the evaluation results of the compared method indicated by grade $H_{3}\left(H_{3}=0.3432\right)$ and $H_{4}\left(H_{4}=0.3472\right)$ are very close to each other, which may lead to an ambiguous condition-assessing result. Therefore, the proposed model can evaluate the health condition of the transformer effectively without ambiguousness, which facilitates the implementation of the maintenance plan.

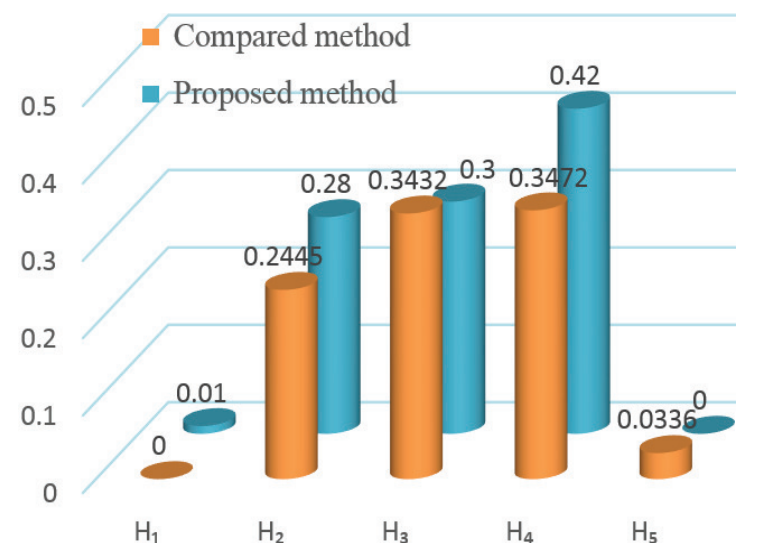

Figure 8. Comparison of the evaluation results of two methods.

\section{Conclusions}

A novel decision-making model, which integrates the merits of fuzzy set theory, game theory and modified evidence combination extended by $\mathrm{D}$ numbers, is proposed in this paper. The presented decision-making model provides a new scientific method for transformer condition assessment. The main results of this paper can be summarized in the following points.

- A four-level framework within three factors, DGA date, electrical testing and oil testing, as well as seventeen sub-indices, has been soundly established to facilitate the evaluation model.

- A comprehensive weight, determined by game theory, can be regarded as an optimum equilibrium solution by reaching a compromise between subjective and objective weight to overcome the limitations of the single weighting method. The subjective weight is given based on the fuzzy extended AHP, which extends traditional AHP and can better address the uncertainty existing in the comparison matrix given by experts. In addition, the objective weight is computed based on the entropy weight method. The final evaluation results can be obtained by the modified evidence combination extended by D numbers. D numbers, a novel theory, can avoid the limitation of the exclusiveness hypothesis in the application of Dempster-Shafer theory. 
- Case studies indicate that the proposed model can effectively reflect the actual health condition of the transformer. Furthermore, compared to the evidential reasoning-based method, the final evaluation result of the presented method can clearly show the health condition of the transformer.

- The proposed approach is not aiming at replacing the expert judgments in the test site or IEC standards. Instead, this paper offers a practical and effective approach for decision-makers, who do not necessarily have in-depth knowledge on power transformers, to evaluate the health condition of power transformers with uncertain and incomplete information.

In the future, several issues can be taken into consideration. First of all, developing a software assessment system based on the proposed model will be recommended. Secondly, some qualitative information could be further taken into consideration in the evaluation model, such as the on-load tap changer, breathing apparatus, etc. Finally, similar applications can be done under other criteria and jobs.

Acknowledgments: The research was supported by the SGCC (State Grid Corporation of China) Thousand program special support project (EPRIPDKJ (2014)2863).

Author Contributions: Lingie Sun and Yingyi Liu conceived of the condition assessment model and wrote most parts of the manuscript. Yuwei Shang and Zhao Ma provided the required input data and wrote parts of the manuscript. Boyang Zhang and Haiwen Yuan analyzed the data and checked the whole paper.

Conflicts of Interest: The authors declare no conflict of interest.

\section{Abbreviations}

The following abbreviations are used in this manuscript:

$\begin{array}{ll}\text { MADM } & \text { multi-attribute decision-making } \\ \text { AHP } & \text { analytic hierarchy process } \\ \text { FAHP } & \text { fuzzy analytic hierarchy process } \\ \text { FEAHP } & \text { fuzzy extended analytic hierarchy process } \\ \text { DGA } & \text { dissolved gas analysis } \\ \text { D-S } & \text { Dempster-Shafer } \\ \text { FST } & \text { fuzzy set theory }\end{array}$

\section{Appendix A. Fuzzy Comparison Matrix}

In this section, the fuzzy comparison matrices of three factors and corresponding indices are given as below. Tables A1-A3 give the corresponding fuzzy comparison matrix for the indices of different factors, and Table A4 shows the fuzzy comparison matrix of three factors (DGA data, oil testing and electrical testing).

Table A1. Fuzzy comparison matrix of the indices of DGA.

\begin{tabular}{cccccc}
\hline Indices & $f_{1 \mathbf{1 1}}$ & $f_{\mathbf{1 2}}$ & $f_{\mathbf{1 3}}$ & $f_{14}$ & $f_{15}$ \\
\hline$f_{11}$ & $(1,1,1)$ & $(1,3 / 2,2)$ & $(2,5 / 2,3)$ & $(2,5 / 2,3)$ & $(3 / 2,2,5 / 2)$ \\
$f_{12}$ & $(1 / 2,2 / 3,1)$ & $(1,1,1)$ & $(3 / 2,2,5 / 2)$ & $(3 / 2,2,5 / 2)$ & $(1,3 / 2,2)$ \\
$f_{13}$ & $(1 / 3,2 / 5,1 / 2)$ & $(2 / 5,1 / 2,2 / 3)$ & $(1,1,1)$ & $(1 / 2,3 / 2,2)$ & $(1 / 2,1,3 / 2)$ \\
$f_{14}$ & $(1 / 3,2 / 5,1 / 2)$ & $(2 / 5,1 / 2,2 / 3)$ & $(1 / 2,2 / 3,2)$ & $(1,1,1)$ & $(1 / 2,1,3 / 2)$ \\
$f_{15}$ & $(2 / 5,1 / 2,2 / 3)$ & $(1 / 2,2 / 3,1)$ & $(2 / 3,1,2)$ & $(2 / 3,1,2)$ & $(1,1,1)$ \\
\hline
\end{tabular}

Table A2. Fuzzy comparison matrix of the indices of the oil testing factor.

\begin{tabular}{cccccccc}
\hline Indices & $f_{21}$ & $f_{22}$ & $f_{23}$ & $f_{24}$ & $f_{25}$ & $f_{26}$ & $f_{27}$ \\
\hline$f_{21}$ & $(1,1,1)$ & $(1 / 2,2 / 3,1)$ & $(1 / 3,1 / 2,2 / 3)$ & $(2,5 / 2,3)$ & $(1 / 2,1,3 / 2)$ & $(1 / 2,1,3 / 2)$ & $(3 / 2,2,5 / 2)$ \\
$f_{22}$ & $(1,3 / 2,2)$ & $(1,1,1)$ & $(1 / 2,1,3 / 2)$ & $(5 / 2,3,7 / 2)$ & $(1,3 / 2,2)$ & $(1,3 / 2,2)$ & $(2,5 / 2,3)$ \\
$f_{23}$ & $(3 / 2,2,3)$ & $(2 / 3,1,2)$ & $(1,1,1)$ & $(5 / 2,3,7 / 2)$ & $(3 / 2,2,5 / 2)$ & $(3 / 2,2,5 / 2)$ & $(2,5 / 2,3)$ \\
$f_{24}$ & $(1 / 3,2 / 5,1 / 2)$ & $(2 / 7,1 / 3,2 / 5)$ & $(2 / 7,1 / 3,2 / 5)$ & $(1,1,1)$ & $(1 / 2,2 / 3,1)$ & $(1 / 2,2 / 3,1)$ & $(1 / 2,1,3 / 2)$ \\
$f_{25}$ & $(2 / 3,1,2)$ & $(1 / 2,2 / 3,1)$ & $(2 / 5,1 / 2,2 / 3)$ & $(1,3 / 2,2)$ & $(1,1,1)$ & $(1,1,1)$ & $(3 / 2,2,5 / 2)$ \\
$f_{26}$ & $(2 / 3,1,2)$ & $(1 / 2,2 / 3,1)$ & $(2 / 5,1 / 2,2 / 3)$ & $(1,3 / 2,2)$ & $(1,1,1)$ & $(1,1,1)$ & $(3 / 2,2,5 / 2)$ \\
$f_{27}$ & $(2 / 5,1 / 2,2 / 3)$ & $(1 / 3,2 / 5,1 / 2)$ & $(1 / 3,2 / 5,1 / 2)$ & $(2 / 3,1,2)$ & $(2 / 5,1 / 2,2 / 3)$ & $(2 / 5,1 / 2,2 / 3)$ & $(1,1,1)$ \\
\hline
\end{tabular}


Table A3. Fuzzy comparison matrix of the indices of the electrical testing factor.

\begin{tabular}{cccccc}
\hline Indices & $f_{31}$ & $f_{32}$ & $f_{33}$ & $f_{34}$ & $f_{35}$ \\
\hline$f_{31}$ & $(1,1,1)$ & $(1,3 / 2,2)$ & $(2,5 / 2,3)$ & $(2,5 / 2,3)$ & $(3 / 2,2,2)$ \\
$f_{32}$ & $(1 / 2,2 / 3,1)$ & $(1,1,1)$ & $(3 / 2,2,5 / 2)$ & $(3 / 2,2,5 / 2)$ & $(1,3 / 2,2)$ \\
$f_{33}$ & $(1 / 3,2 / 5,1 / 2)$ & $(2 / 5,1 / 2,2 / 3)$ & $(1,1,1)$ & $(1 / 2,3 / 2,2)$ & $(1 / 2,1,1)$ \\
$f_{34}$ & $(1 / 3,2 / 5,1 / 2)$ & $(2 / 5,1 / 2,2 / 3)$ & $(1 / 2,2 / 3,1)$ & $(1,1,1)$ & $(1 / 2,1,1)$ \\
$f_{35}$ & $(1 / 2,1 / 2,2 / 3)$ & $(1 / 2,2 / 3,1)$ & $(1,1,2)$ & $(1,1,2)$ & $(1,1,1)$ \\
\hline
\end{tabular}

Table A4. Fuzzy comparison matrix of three factors.

\begin{tabular}{cccc}
\hline Indices & $f_{41}$ & $f_{42}$ & $f_{43}$ \\
\hline$f_{41}$ & $(1,1,1)$ & $(3 / 5,1,4 / 3)$ & $(3 / 2,2,5 / 2)$ \\
$f_{42}$ & $(3 / 4,1,5 / 3)$ & $(1,1,1)$ & $(2 / 3,1,3 / 2)$ \\
$f_{43}$ & $(2 / 5,1 / 2,2 / 3)$ & $(2 / 3,1,3 / 2)$ & $(1,1,1)$ \\
\hline
\end{tabular}

\section{References}

1. Wang, C.; Wu, J.; Wang, J.; Zhao, W. Reliability analysis and overload capability assessment of oil-immersed power transformers. Energies 2016, 9, 43.

2. Jahromi, A.; Piercy, R.; Cress, S.; Fan, W. An approach to power transformer asset management using health index. IEEE Electr. Insul. Mag. 2009, 2, 20-34.

3. Murugan, R.; Ramasamy, R. Failure analysis of power transformer for effective maintenance planning in electric utilities. Eng. Fail. Anal. 2015, 55, 182-192.

4. Wang, M.; Vandermaar, A.J.; Srivastava, K.D. Review of condition assessment of power transformers in service. IEEE Electr. Insul. Mag. 2002, 18, 12-25.

5. Tang, W.H.; Spurgeon, K.; Wu, Q.H.; Richardson, Z.J. An evidential reasoning approach to transformer condition assessments. IEEE Trans. Power Deliv. 2004, 19, 1696-1703.

6. Liao, R.; Stanislaw Grzybowski, H.Z.; Yang, L.; Zhang, Y.; Liao, Y. An integrated decision-making model for condition assessment of power transformers using fuzzy approach and evidential reasoning. IEEE Trans. Power Deliv. 2011, 26, 1111-1118.

7. Illias, H.A.; Chai, X.R.; Mokhlis, H. Transformer incipient fault prediction using combined artificial neural network and various particle swarm optimisation techniques. PLoS ONE 2015, 10, e0129363.

8. Cui, Y.; Ma, H.; Saha, T. Improvement of power transformer insulation diagnosis using oil characteristics data preprocessed by smoteboost technique. IEEE Trans. Dielectr. Electr. Insul. 2014, 21, 2363-2373.

9. Abu-Siada, A.; Hmood, S. A new fuzzy logic approach to identify power transformer criticality using dissolved gas-in-oil analysis. Int. J. Electr. Power 2015, 67, 401-408.

10. Lin, P.-C.; Yang, M.-T.; Gu, J.-C. Intelligent maintenance model for condition assessment of circuit breakers using fuzzy set theory and evidential reasoning. IET Gener. Transm. Distrib. 2014, 8, 1244-1253.

11. Gaudenzi, B.; Borghesi, A. Managing risks in the supply chain using the AHP method. Int. J. Logist. Manag. 2006, 17, 114-136.

12. Al-Harbi, K.M.A.-S. Application of the AHP in project management. Int. J. Proj. Manag. 2001, $19,19-27$.

13. Okello, C.; Pindozzi, S.; Faugno, S.; Boccia, L. Appraising bioenergy alternatives in Uganda using strengths, weaknesses, opportunities and threats (SWOT)-analytical hierarchy process (AHP) and a desirability functions approach. Energies 2014, 7, 1171-1192.

14. Liu, K.-S.; Hsueh, S.-L.; Wu, W.-C.; Chen, Y.-L. A DFuzzy-DAHP decision-making model for evaluating energy-saving design strategies for residential buildings. Energies 2012, 5, 4462-4480.

15. Saaty, T.L. The Analytic Hierarchy Process; McGraw-Hill: New York, NY, USA, 1980.

16. Saaty, T.L. How to make a decision: The analytic hierarchy process. Interfaces 1994, 24, $19-43$.

17. Dempster, A.P. Upper and lower probabilities induced by a multivalued mapping. Ann. Math. Stat. 1967, 38, 325-339.

18. Shafer, G. A Mathematical Theory of Evidence; Princeton University Press: Princeton, NJ, USA, 1976. 
19. Wang, H.; Lin, D.; Qiu, J.; Ao, L.; Du, Z.; He, B. Research on multiobjective group decision-making in condition-based maintenance for transmission and transformation equipment based on D-S evidence theory. IEEE Trans. Smart Grid 2015, 6, 1035-1045.

20. Deng, H. Multicriteria analysis with fuzzy pairwise comparison. Int. J. Approx. Reason. 1999, 21, $215-231$.

21. Abu-Elanien, A.E.B.; Salama, M.M.A.; Ibrahim, M. Calculation of a health index for oil-immersed transformers rated under $69 \mathrm{kV}$ using fuzzy logic. IEEE Trans. Power Deliv. 2012, 27, 2029-2036.

22. Mikhailov, L.; Tsvetinov, P. Evaluation of services using a fuzzy analytic hierarchy process. Appl. Soft Comput. 2004, 5, 23-33.

23. Lai, C.; Chen, X.; Chen, X.; Wang, Z.; Wu, X.; Zhao, S. A fuzzy comprehensive evaluation model for flood risk based on the combination weight of game theory. Nat. Hazards 2015, 77, 1243-1259.

24. Deng, Y. D numbers: Theory and applications. J. Inf. Comput. Sci. 2012, 9, 2421-2428.

25. Deng, X.; Lu, X.; Chan, F.T.S.; Sadiq, R.; Mahadevan, S.; Deng, Y. D-CFPR: D numbers extended consistent fuzzy preference relations. Knowl.-Based Syst. 2015, 73, 61-68.

26. Li, M.; Hu, Y.; Zhang, Q.; Deng, Y. A novel distance function of D numbers and its application in product engineering. Eng. Appl. Artif. Intell. 2016, 47, 61-67.

27. Chang, D.-Y. Application of the extent analysis method on fuzzy AHP. Eur. J. Oper. Res. 1999, 95, 649-655.

28. Wang, X.; Chan, H.K.; Li, D. A case study of an integrated fuzzy methodology for green product development. Eur. J. Oper. Res. 2015, 241, 212-223.

29. Uğurlu, Ö. Application of fuzzy extended AHP methodology for selection of ideal ship for oceangoing watchkeeping officers. Int. J. Ind. Ergon. 2015, 47, 132-140.

30. Chen, J.-F.; Hsieh, H.-N.; Do, Q.H. Evaluating teaching performance based on fuzzy AHP and comprehensive evaluation approach. Appl. Soft Comput. 2015, 28, 100-108.

31. Sanfey, A.G. Social decision-making: Insights from game theory and neuroscience. Science 2007, 318, 598-602.

32. Frank, D.M.; Sarkar, S. Group decisions in biodiversity conservation: Implications form game theory. PLOS ONE 2010, 5, e10688.

33. Deng, X.; Hu, Y.; Deng, Y.; Mahadevan, S. Environmental impact assessment based on D numbers. Expert Syst. Appl. 2014, 41, 635-643.

34. Fan, G.; Zhong, D.; Yan, F.; Yue, P. A hybrid fuzzy evaluation method for curtain grouting efficiency assessment based on an AHP method extended by D numbers. Expert Syst. Appl. 2016, 44, 289-303.

35. Dhote, N.K.; Helonde, J.B. Improvement in transformer diagnosis by DGA using fuzzy logic. J. Electr. Eng. Technol.2014, 9, 615-621.

36. Liu, C.H.; Lin, T.B.; Yao, L.; Wang, S.Y. Integrated power transformer diagnosis using hybrid fuzzy dissolved gas analysis. IEEJ Trans. Electr. Electron. Eng. 2015, 10, 689-698.

37. Buyukozkam, G.; Kahraman, C.; Ruan, C. A fuzzy multi-criteria decision approach for software development sratege selection. Int. J. Gen. Syst 2004, 33, 259-280.

38. Shannon, C. A mathematical theory of communication. Bell Syst. Tech. J. 1948, 27, 379-423, 623-656.

39. Li, L.H.; Mo, R. Production task queue optimization based on multi-attribute evaluation for complex product assembly workshop. PLoS ONE 2015, 10, e0134343.

40. Zhao, H.; Li, N. Optimal siting of charging stations for electric vehicles based on fuzzy Delphi and hybrid multi-criteria decision making approaches from an extended sustainability perspective. Energies 2016, 9, 270.

41. Deng, Y.; Shi, W.; Zhu, Z.; Liu, Q. Combining belief functions based on distance of evidence. Decis. Support Syst. 2004, 38, 489-493.

42. Yasinzadeh, M.; Seyedi, H. Fake measurement identification in power substations based on correlation between data and distance of the evidence. IET Gener. Transm. Distrib. 2015, 9, 503-512.

(C) 2016 by the authors; licensee MDPI, Basel, Switzerland. This article is an open access article distributed under the terms and conditions of the Creative Commons Attribution (CC-BY) license (http:/ / creativecommons.org/licenses/by/4.0/). 